\title{
Energy Saving and Economic Analysis of Switched Reluctance Motor in Agricultural Applications
}

\author{
A Asok Kumar ${ }^{1}$ (D) $\cdot$ G R Bindu ${ }^{2} \cdot$ Elizabeth Cherian ${ }^{1} \cdot$ M. L. Parvathy ${ }^{2}$ \\ Received: 3 August 2019 / Accepted: 13 December 2019 / Published online: 26 December 2019 \\ (C) Springer Nature Singapore Pte Ltd. 2019
}

\begin{abstract}
Improvement of efficiency in electrical machines for water lifting applications in agricultural sector results in large energy savings, which is very much important in the present scenario of energy crisis. Single and three phase induction motors are most commonly used in such applications. However, these machines consume more energy due to their low efficiencies. A comprehensive performance evaluation including the machine design, selection of converter topologies, method of control, practical implementation of drive system, and vibration analysis for an agriculture applications is not done so far. This paper discuses to design Switched Reluctance Motor suitable for use in agricultural applications. Select suitable drive systems for this motor, giving considerations to lower switching losses and easiness of control. To investigate suitable control strategies for the speed control of the motor. Experimental validation of the performances of the motor, along with the vibration analysis. A real time experiment is also conducted to demonstrate the suitability of Switched Reluctance Motor drive for water lifting application and finally, per year unit consumption of Single Phase Induction Motor and Switched Reluctance Motor are compared to prove the economic superiority of Switched Reluctance Motor.
\end{abstract}

Keywords Electrical drives $\cdot$ Converters $\cdot$ Inverters $\cdot$ Switched reluctance motor $\cdot$ Finite element analysis $\cdot$ Modelling $\cdot$ Vibrations

\section{Introduction}

Efficiency improvement of agricultural motors outcome in considerable overall energy savings, which is extremely significant with respect to global energy deficit scenario. In agricultural applications, commonly used Single Phase

A Asok Kumar

asokkumarsuma@gmail.com

G R Bindu

bgr100@gmail.com

Elizabeth Cherian

ecjp2015@gmail.com

M. L. Parvathy

parvathyml@yahoo.com

1 Dept. of Electrical \& Electronics Engineering, Govt. Engineering College Barton Hill, Thiruvananthapuram, Kerala, India

2 Dept. of Electrical Engineering, College of Engineering Trivandrum, Thiruvananthapuram, Kerala, India
Induction Motor (SPIM) consume more power, due to their low efficiencies. As per the energy statistics for the year 2016$2017,18 \%$ of total generated electrical energy is utilized by the agriculture sector which is the third largest electrical energy usage sector in India [1]. Thus, even a small reduction in the energy wastage for each unit results in a larger improvement cumulatively. Hence this paper attempts to look into an alternative to SPIM, so that a massive energy saving results in the agricultural sector. A special electrical machines like Switched Reluctance Motor (SRM) is finding new avenues of application, thanks to the rapid development of power electronic technology.

Hence the objectives of this paper are as follows:

- To design the SRM suitable for agricultural applications based on specific requirements.

- To select suitable drive system for this motor, giving considerations to lower switching losses and easiness of control.

- To investigate suitable control strategies for the speed control of the motor.

- To analyze the performance of the machine with a view for energy conservation. 
Fig. 1 DC Split Supply Converter

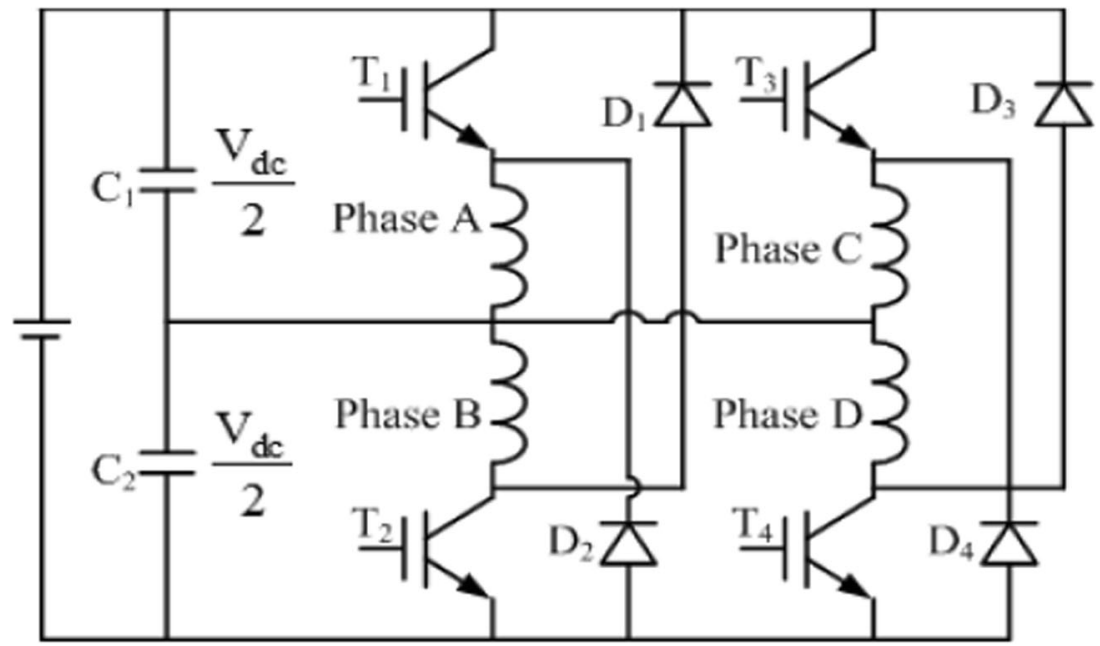

- Experimental validation of the performance of the selected motor, namely, SRM.

- To conduct the vibration analysis of SRM and

- Compare the energy consumption of SRM and SPIM by performing an economic analysis.

\section{Literature Review}

The state of the art and trends along with different application possibilities of SR machines are discussed in [2-8]. The simple electric motors in domestic appliances and electric vehicles are increasingly being replaced by drive based systems [9, 10]. Power electronic devices used in such systems help to obtain an efficient motor drive which operate over a wide range of speed with simultaneous reduction in losses. Optimizing the performance and reduction of complexities are important while implementing converters in SRM drives [11-14]. Energy saving efforts in a major consumption sector like agriculture demands a comprehensive analysis of the performance of SRM drives when utilized exclusively in that area.

This paper deals with the design of SRM along with its controller that can be used in water lifting application in agricultural sector. Different methods of controllers are implemented in different power system problems including the optimization algorithms [15-18]. In the implementation stage, many speed control techniques of drive systems such as PI control, sliding mode control and artificial neural network control applied in SRM are suggested [19-21]. However, PI based control method is commonly adopted due to the advantages such as the easiness of the implementation of control strategy, precise control in the transient and steady state period of operation etc. of the system [22].
The performance analysis of SRM can be accurately done using Finite Element Method (FEM) so that nonlinearity, saturation of flux, material property and actual geometry are included [23, 24].

SRM generally produces high acoustic noise due to vibration. Many studies are going on to find the reasons for the same and the development of different control strategies [25]. The study discusses a simple algorithm for estimation and reduction of vibration in SRM [26]. Applying different excitation methods such as single phase excitation, PWM voltage control excitation etc., to develop an anti-phase vibration for mitigating the vibration of SRM is discussed in [27]. Research for controlling the vibration and acoustic noise of SRM by using different converter control strategy are presented in $[28,29]$.

From the literature survey, it is observed that a comprehensive comparative study of such motors (SRM \& SPIM) has not been done so far, for specific applications, with a view of energy conservation. Hence, replacing an old generation motor like SPIM with a new generation power converter based

Table 1 Designed Values of SRM for use of FEM Analysis

\begin{tabular}{ll}
\hline Parameters & SRM \\
\hline Load & Constant Power \\
Axial Length of core (mm) & 45 \\
Stator diameter (Outer) (mm) & 105 \\
Stator diameter (Inner)(mm) & 55 \\
Main-Phase Wire Diameter (mm) & 0.683 \\
Air Gap (mm) & 0.25 \\
Rotor diameter (Inner) (mm) & 15 \\
Number of Turns per Pole & 200 \\
Yoke Thickness (mm) & 12.5 \\
\hline
\end{tabular}




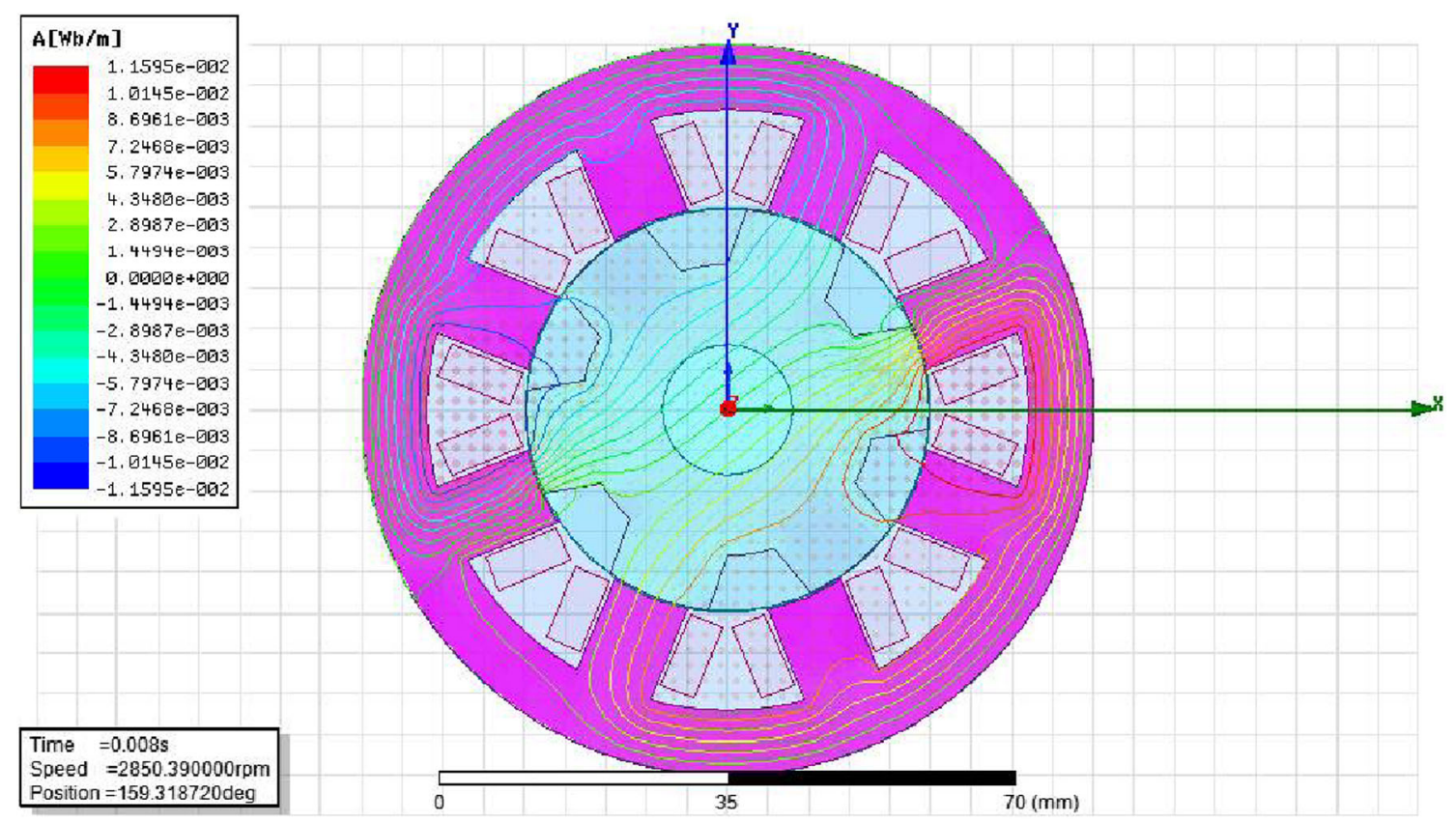

Fig. 2 Cross sectional view of FEM Model

motor like SRM in domestic appliances and agricultural applications may reduce the energy consumption to a great deal and is an area which needs a detailed analysis.

The remaining section of this paper is organized as follows. Section 3 deals with the design and performance analysis of SRM by FEM. Section 4 presents the mathematical modelling of SRM drive including motor, converter and controller and the simulation results. In section 5 , the experimental validation of SRM drive characteristics are presented. The vibration analysis of the designed SRM drive is given in section 6. Section 7 establishes the superiority of SRM over SPIM, based on real time implementation and Section 8 gives the conclusion.

\section{Design of SRM and Performance Analysis by FEM}

A converter circuit is required for giving a pulsed waveform for controlling the phase current of SRM. Current through the phase winding is controlled by a converter, so that the converter develops pulsed waveform for SRM drive systems.

In early 1990's several inverter or converter power circuits suitable for SRM drives are analyzed and compared [30, 31]. The selection of suitable converter and control scheme for a specific application depends on the performance requirements, configuration of SRM, cost etc. Since this paper focuses on agricultural applications, an SRM of $8 / 6$ configuration is chosen. Hence the selection of converter topology depends on this aspects also.

The following conditions are considered for the selection of converter: 1. Each phase of the SRM should be excited independently. At least one switch per phase should be provided for the motor operation. 2. A demagnetizing possibility is provided, if the machine is operated in regenerating region and vice versa.

3. The selected converter should be able to give higher efficiency, fast excitation time, fast demagnetization, high power and fault tolerance. In low rated applications, SRM is used with DC split supply converter as shown in Fig. 1 [32-34].

The performances of this type converter is efficient due to the less number of switches, and the cost is minimum. Hence DC split supply converter is used in this work. The design and performance analysis of SRM is done in three steps:

- The specifications of SRM which is required for the particular application is first fixed. In agricultural and domestic sector, the existing motor is SPIM which has a power output ranging from $70 \mathrm{~W}$ to $750 \mathrm{~W}$, with a speed range of 1000 to $5000 \mathrm{rpm}$ and torque range in between $0.75 \mathrm{Nm}$ to $1.75 \mathrm{Nm}$. Based on the above specifications the
Table 2 Output parameters from FEM analysis

\begin{tabular}{ll}
\hline Parameters & Values \\
\hline Rated speed (rpm) & 2850 \\
Input Power (W) & 410.57 \\
Total Loss (W) & 40.58 \\
Output Power (W) & 370.00 \\
Efficiency (\%) & 90.13 \\
Rated Torque (N-m) & 1.24 \\
\hline
\end{tabular}




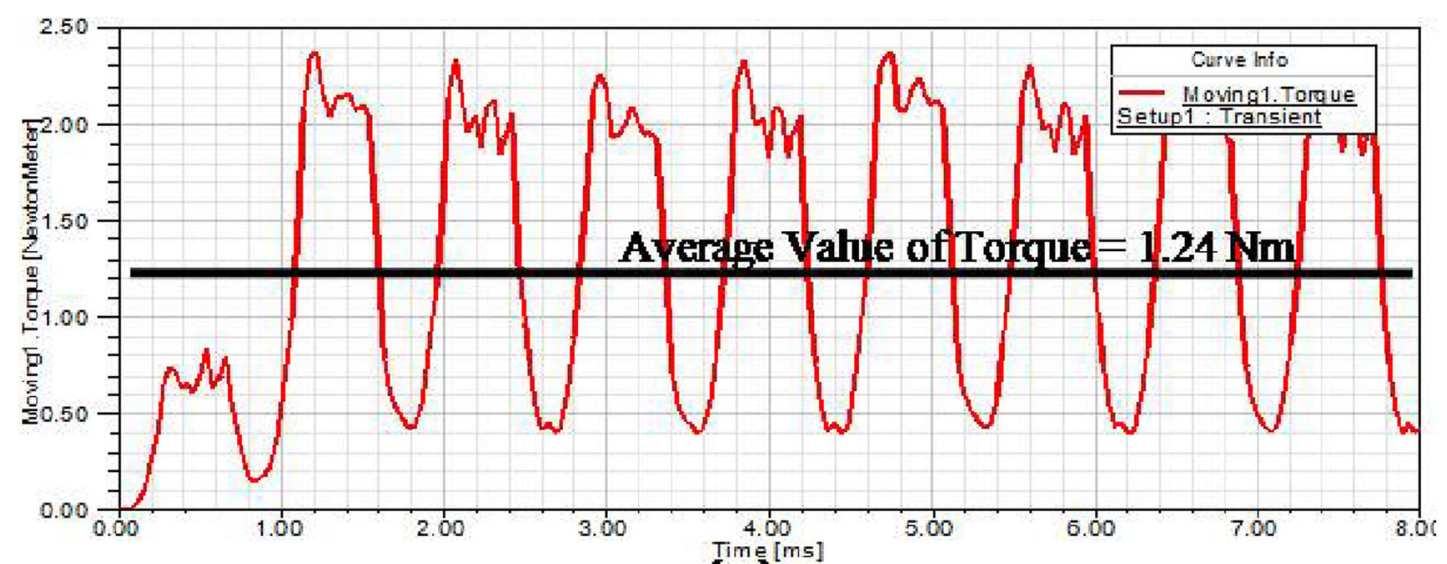

(a)
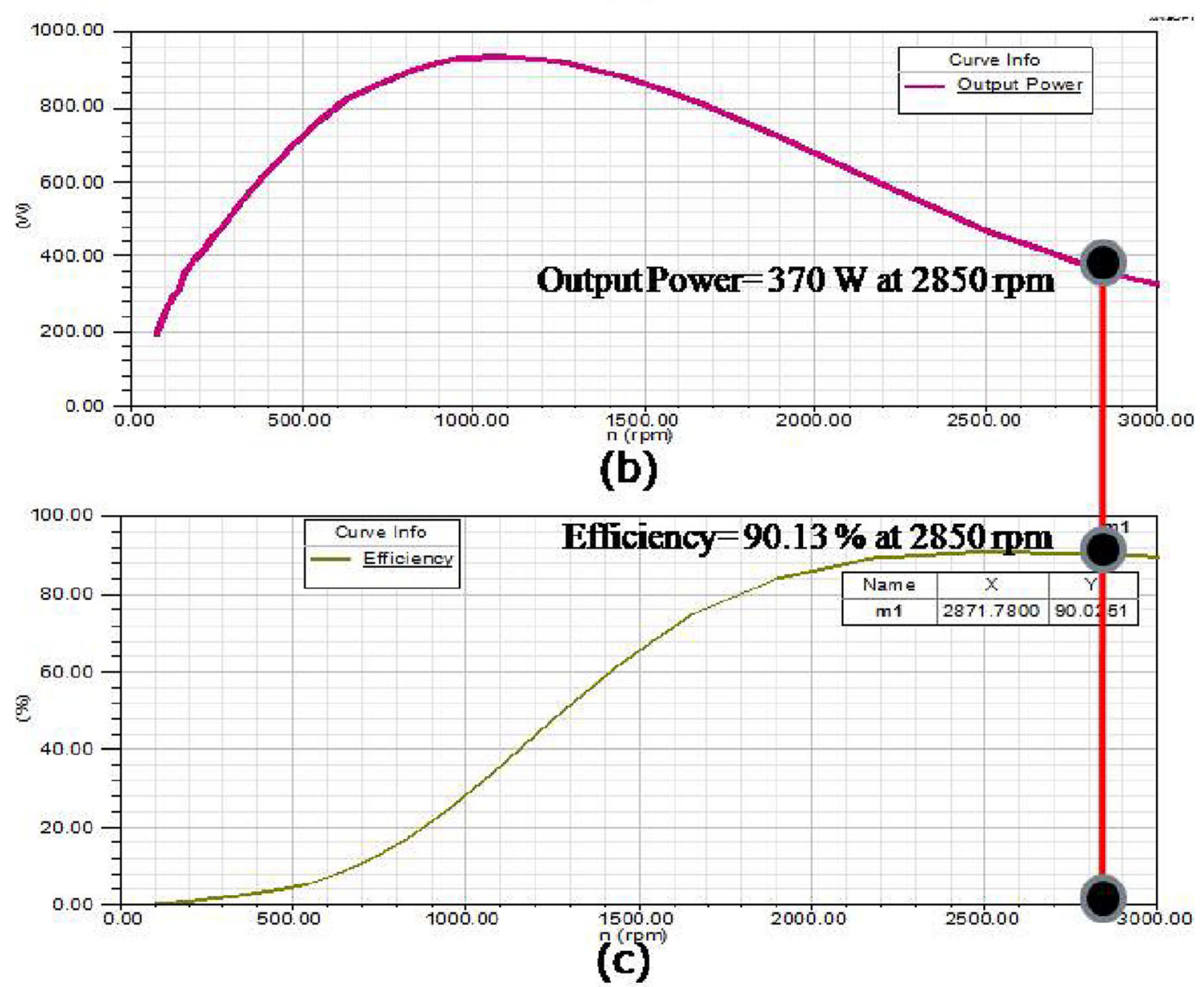

Fig. 3 a Torque Vs Time, b Output Vs Speed, $\mathbf{c}$ Efficiency Vs Speed of SRM at rated condition

parameters of SRM are selected as: $0.37 \mathrm{~kW}$ power output, $240 \mathrm{~V}$ supply voltage, $2850 \mathrm{rpm}$ rated speed, 1.24 torque and $8 / 6$ stator rotor pole configuration.

- Next the machine dimensions are analytically determined for the specifications in Table 1 and the obtained values are tabulated in Table 1. The core material is selected as M19 core. The detailed design is discussed in a previous paper of the authors [35]. The supply frequency $(f)$, step angle $\left(\theta_{s}\right)$ and the number of stator phases $\left(N_{s}\right)$ will determine the speed of motor.

The motor speed $(N)$ can be calculated as in eq. (1),

$N=\frac{f \times \theta_{s} \times N_{s} \times 60}{360^{0}}$ 


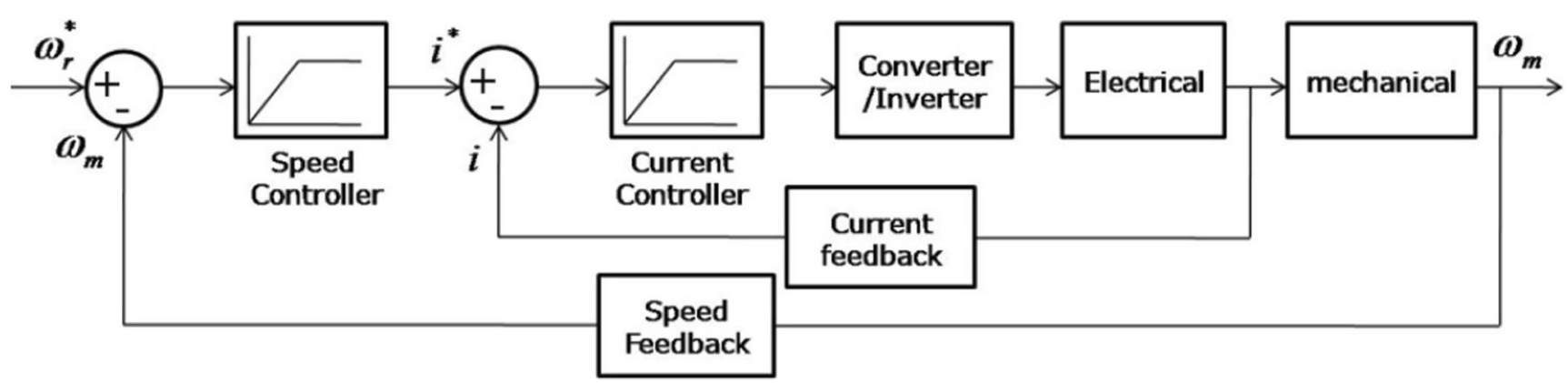

Fig. 4 Block diagram of general drive system control scheme

The rotor stator combination of selected motor is $8 / 6$, the $\theta_{s}$ is $15^{0}$ with a synchronous speed of $3000 \mathrm{rpm}$, the switching frequency of each phase should be $300 \mathrm{~Hz}$.

Finally, an FE model of the designed SRM is developed as shown in Fig. 2. Analysis of radial flux electrical machines necessitates a 2-D finite model only [36]. The performance analysis of SRM is done with the Ansoft Maxwell 2-D design software. The output parameters obtained by FE analysis are tabulated in Table 2. Figure 3 shows the variation of torque, output power and efficiency of the designed machine at rated condition.

From the FE analysis, the average torque developed is found to be $1.24 \mathrm{Nm}$ as shown in Fig. 3(a). The output power at rated speed of $2850 \mathrm{rpm}$ is $370 \mathrm{~W}$ and the corresponding efficiency is $90.13 \%$ as shown in Fig. 3(b) and (c) respectively.

\section{Modelling of SRM Drive System}

The development of control technique of drive system requires a mathematical model analysis. Figure 4 shows the general control scheme of electric motor drive used for modelling. It involves modelling of SRM, its converter, development of inner current loops and overall transfer function as well as design of speed controller. A linearized reduced order mathematical model of SRM is developed as given by eq. 2 $[37,38]$.

$\frac{\delta \omega_{m}(s)}{\delta V_{s}}=\left[K_{1} \frac{\left(1+s T_{m}\right)}{\left(1+s T_{1}\right)\left(1+s T_{2}\right)} \frac{K_{b} / B_{t}}{\left(1+s T_{m}\right)}\right]$

where, $B_{t}=B+B_{l}, K_{1}=\frac{B_{t}}{K_{b}^{2} R_{e q} B_{t}}, T_{m}=\frac{J}{B_{t}}, \omega_{m}$ is the output speed, $V_{s}$ is the supply voltage, $R_{e q}$ is the equivalent
Fig. 5 a Inner Current Loop, b Reduced Current Loop, c Speed Loop and $\mathbf{d}$ Speed Controller System

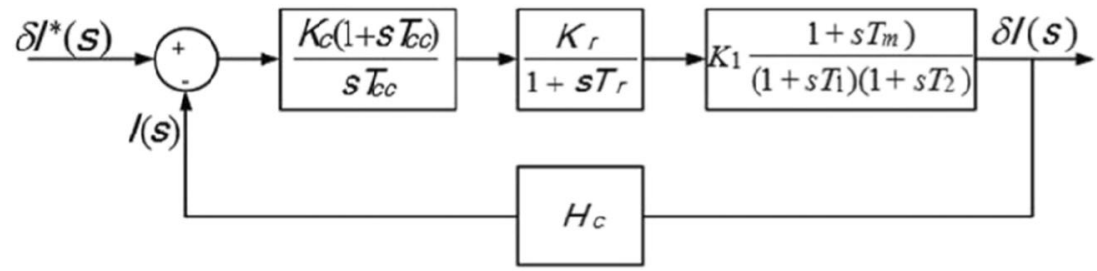

(a)

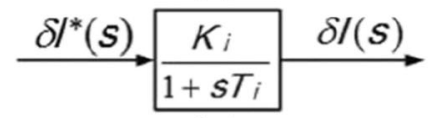

(b)

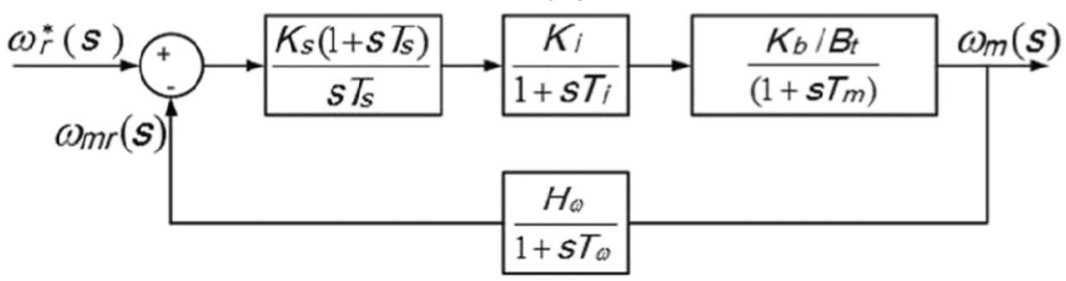

(c)

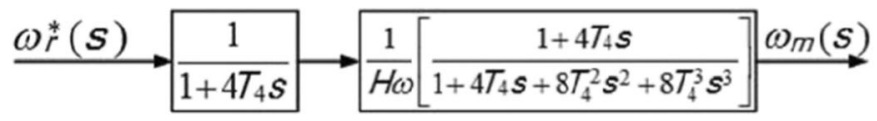

(d) 
Table 3 Parameters used for modelling of SRM

\begin{tabular}{ll}
\hline Parameters & Values \\
\hline Winding resistance, $R_{m}(\Omega)$ & 1.04 \\
Winding inductance, $L_{m}(H)$ & 0.08 \\
Inertia, $J\left(K_{g m^{2}}\right)$ & 0.00016 \\
Frictional constant & 0.0005 \\
Current, $I(A)$ & $1.74(\mathrm{rms})$ \\
\hline
\end{tabular}

resistance, $B$ is the viscous friction coefficient, $B_{l}$ is the load constant, $T_{m}$ is mechanical time constant, $K_{b}$ is the emf constant.

The transfer function of split space dc converter is derived as in eq. (3).

$G_{r}(s)=\frac{v_{s}}{v_{s}^{*}}=\frac{K_{r}}{1+s T_{r}}$

where, $v_{s}$ is the converter output voltage, $v_{s}^{*}$ is the converter input voltage, $K_{r}$ is the converter gain, $T_{r}$ is the converter time constant.

Referring to Fig. 4, it is clear that the control scheme consists of two loops viz. the current loop and the speed loop. For the inner current loops a PI controller is selected as shown in Fig. 5(a) which can be reduced to a model as in Fig. 5(b) The outer speed loop is developed along with PI controller and the inner current loop as in Fig. 5(c) which is further simplified as in Fig. 5(d). Table 3 shows the different parameters obtained by FE analysis which are used for the actual modelling of the selected SRM drive. The control parameters so obtained are $K s=0: 223$ and $T s=0: 308$. Figure 6 represents the complete block schematic of actual SRM drive system. Simulations are performed on this model for further analysis.

Figure 6 represents the complete block schematic of actual SRM drive system. Simulations are performed on this model for further analysis.

Simulations are performed on MATLAB - Simulink platform and the speed responses of SRM drive obtained are shown in Fig. 7(a) and (b) respectively. From the analysis it is observed that SRM has a better dynamic performance and the response settles much faster to the reference speed of 1000, 2000 and $2850 \mathrm{rpm}$. The time domain specifications are tabulated in Table 4. To investigate the capability of motors in different speed ranges, the reference speed is changed during their operation from $1500 \mathrm{rpm}$ to $2850 \mathrm{rpm}$ (Fig. 7(b)).
Simulation results reveal the satisfactory operation of SRM drive in terms of speed adaptation and time domain specifications.

\section{Experimental Validation of SRM Drive}

An experimental study is conducted on the designed and fabricated $370 \mathrm{~W}, 8 / 6$ four phase SRM for establishing the simulation results. The designed parameters obtained from the classical design method and FE analysis are used to fabricate the SRM. The designed SRM along with the specified converter and control topology are physically realized. The PI controller is implemented with a S320F28335 DSP processor. The IGBT device used in the converter is 1MBH60D-090A. The rotor position is sensed and changes in every $15^{\circ}$. The experimental setup of the drive system as shown in Fig. 8.

The drive system is runs at a speed of $2850 \mathrm{rpm}$ and $2000 \mathrm{rpm}$ with different loads. The experiment is started with no load condition. The speed of the motor settles at reference value, load is applied. The speed response shows (Fig. 9) the effectiveness of load. In an open loop system, speed changes due to the load, and still the changed speed is maintained. However, the response regains immediately in closed loop control to the reference speed. So that the speed regulation capability and the time response performance are better in the closed loop system under any load condition.

Different performance characteristics of $370 \mathrm{~W}, 2850 \mathrm{rpm}$, $8 / 6$, four phase SRM are plotted in Fig. 10. Table 5 shows the comparison of different parameters obtained from FEM and experimental studies. A significant finding from the experiment is that the SRM exhibit a high efficiency of $86.24 \%$ which is a feature that can be utilized for energy saving in water lifting application in agriculture.

\section{Vibration Analysis}

The analysis of SRM is incomplete without an analysis of its mechanical vibration. The onset of vibrations in SRM can be due to mechanical or magnetic factors. Even though the machine is compact and has fault resilient features, the double salient construction contributes to strong magnetic radial forces which lead to serious vibrations. In this section the FE analysis of radial magnetic force and vibrations under load conditions of SRM are discussed. The simulated results of
Fig. 6 Block schematic of actual drive system

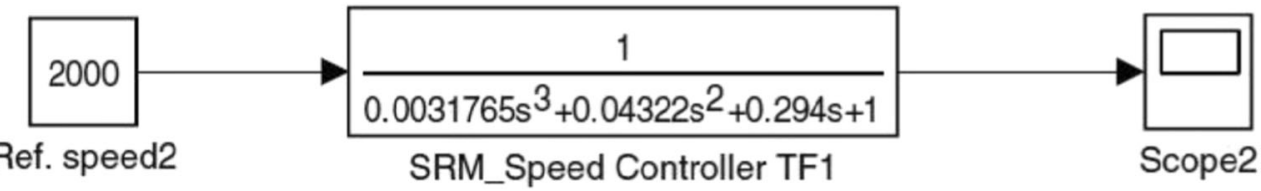


Fig. 7 a Speed Response at 1000 , 2000 and $2850 \mathrm{rpm}$ of SRM, b Speed change from 1500 to $2850 \mathrm{rpm}$

Table 4 Time domain specifications

Fig. 8 Experimental setup

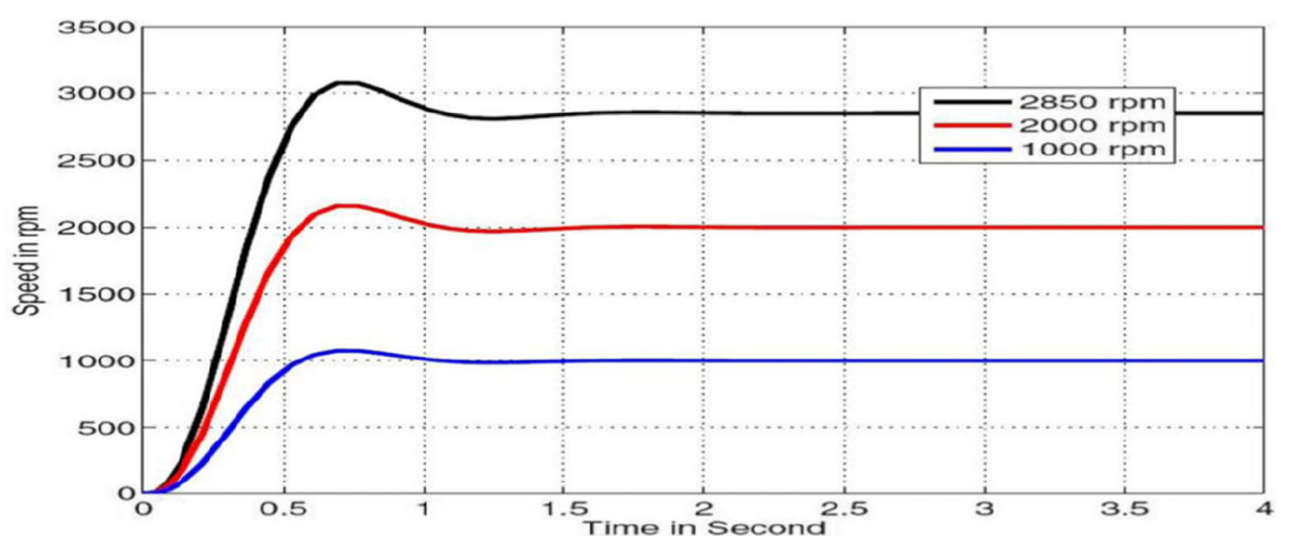

(a)

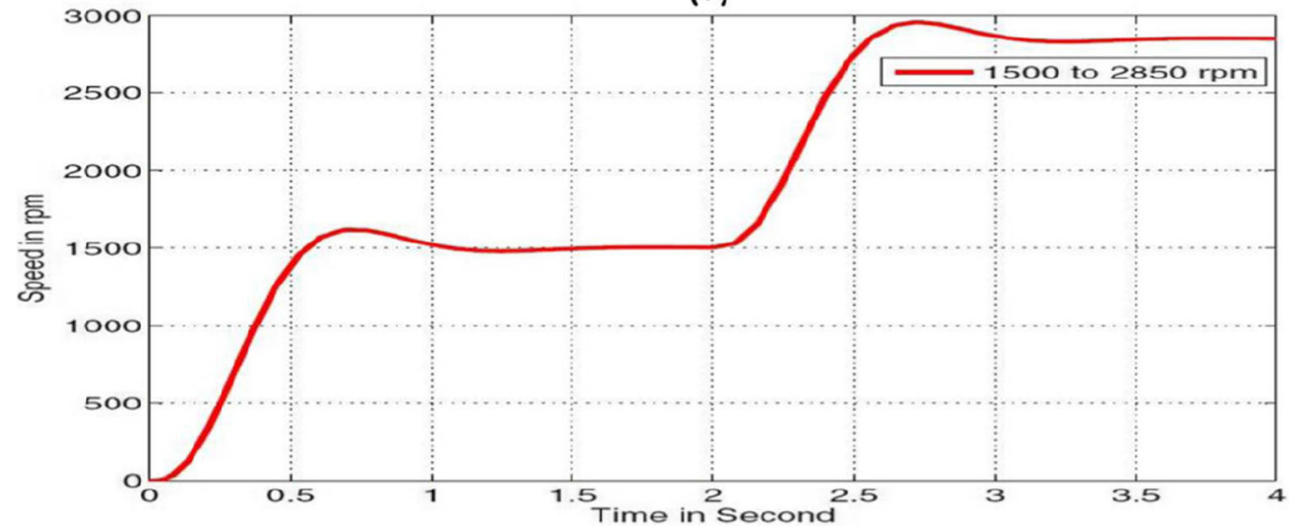

(b)

\begin{tabular}{llll}
\hline Speed (rpm) & Rise Time (Sec.) & Settling Time (Sec.) & Peak Overshoot (rpm) \\
\hline 1000 & 0.55 & 1.70 & 90 \\
2000 & 0.60 & 1.75 & 200 \\
2850 & 0.65 & 1.75 & 250 \\
\hline
\end{tabular}

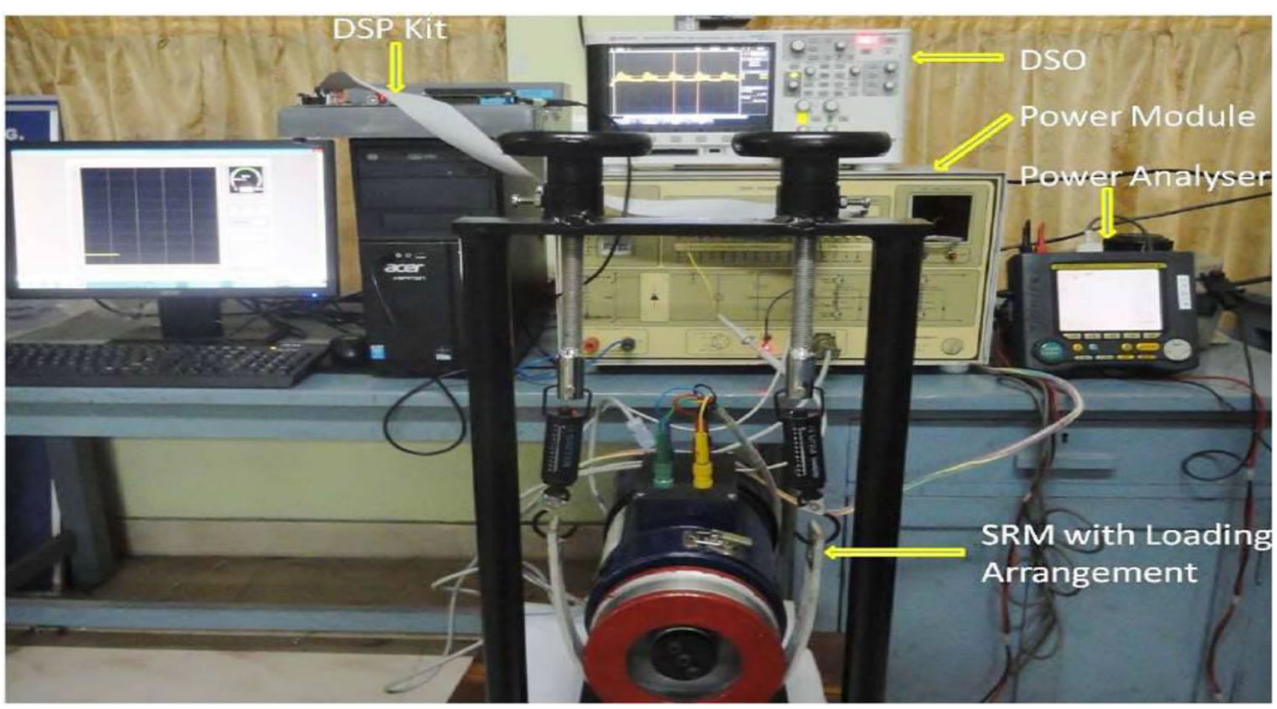


Fig. 9 Open loop and Closed loop Speed response of $2850 \mathrm{rpm}$ and $2000 \mathrm{rpm}$ as viewed on a DSO (750 rpm/div)

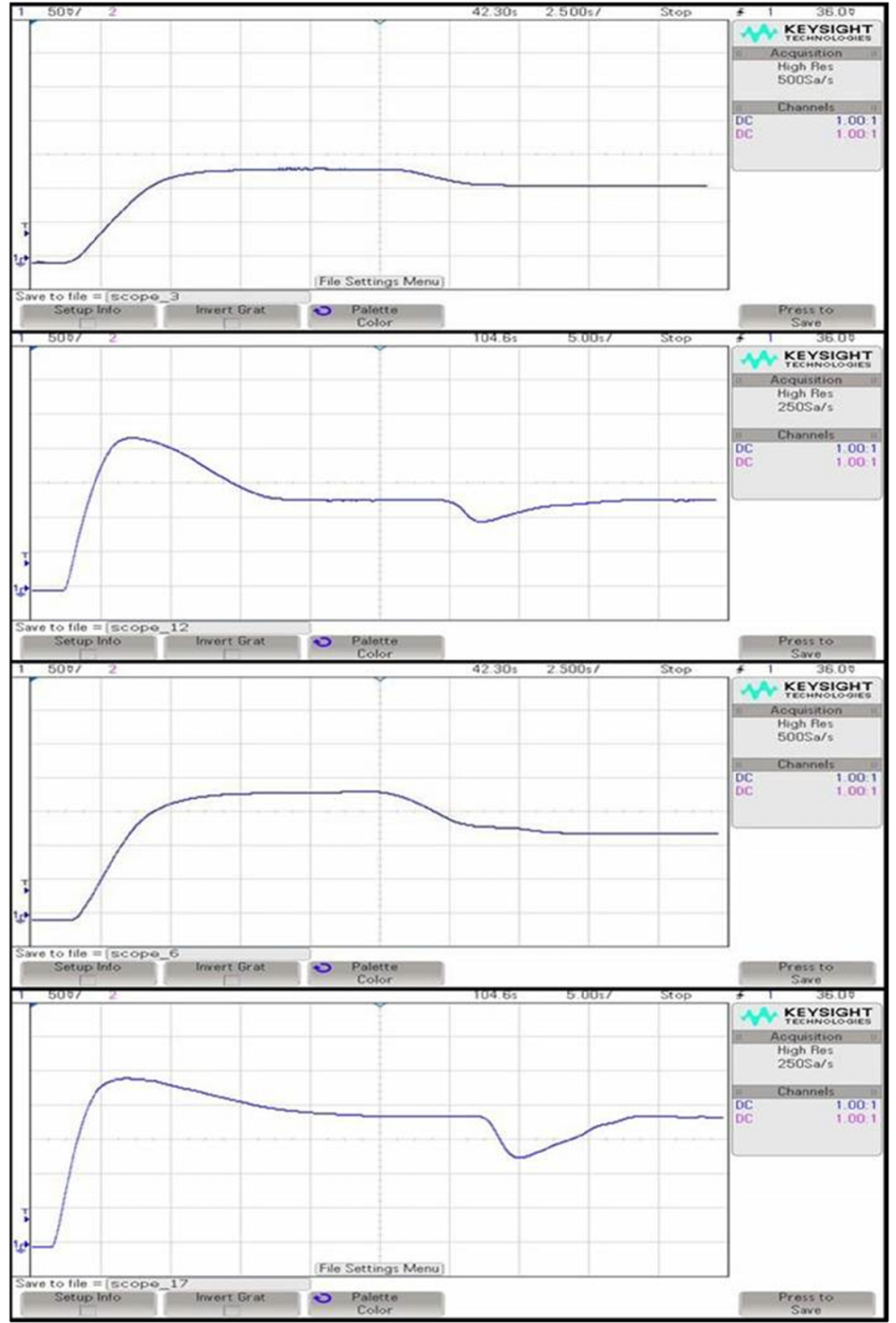

vibration are compared with the measured values obtained experimentally.

\section{FE Analysis of Vibration}

Due to the development of strong radial forces and consequent magnetic attractions, the stator of SRM experiences radial deformation [28]. As the stator itself has a natural frequency, acoustic noises are more likely to be emitted [27, 39]. The FE model of SRM with rated torque of $1.22 \mathrm{Nm}$ (Table 5) is analyzed to obtain the radial forces. Figure 11(a) shows the FFT of radial forces obtained from the analysis. The corresponding variation in amplitude of vibration are shown in Fig. 11(b). The peak value of vibration is obtained as
$2.33 \mathrm{~mm} / \mathrm{s}$. The result indicates that the radial forces and vibrations in this SRM are prominent but below the critical value as specified by the ISO standards (ISO 10816).

\section{Experimental Measurement of Vibration}

Figure 12 shows the experimental setup for vibration measurement using Fluke 810 vibration tester. A load corresponding to a torque of $1.22 \mathrm{Nm}$ is applied and the lower and higher order frequency responses are measured as shown in Fig. 13(a) and (b). The vibration obtained for this load is having a peak value of $2.45 \mathrm{~mm} / \mathrm{s}$., which is in close agreement with the simulation result. 
Fig. 10 Performance Characteristics
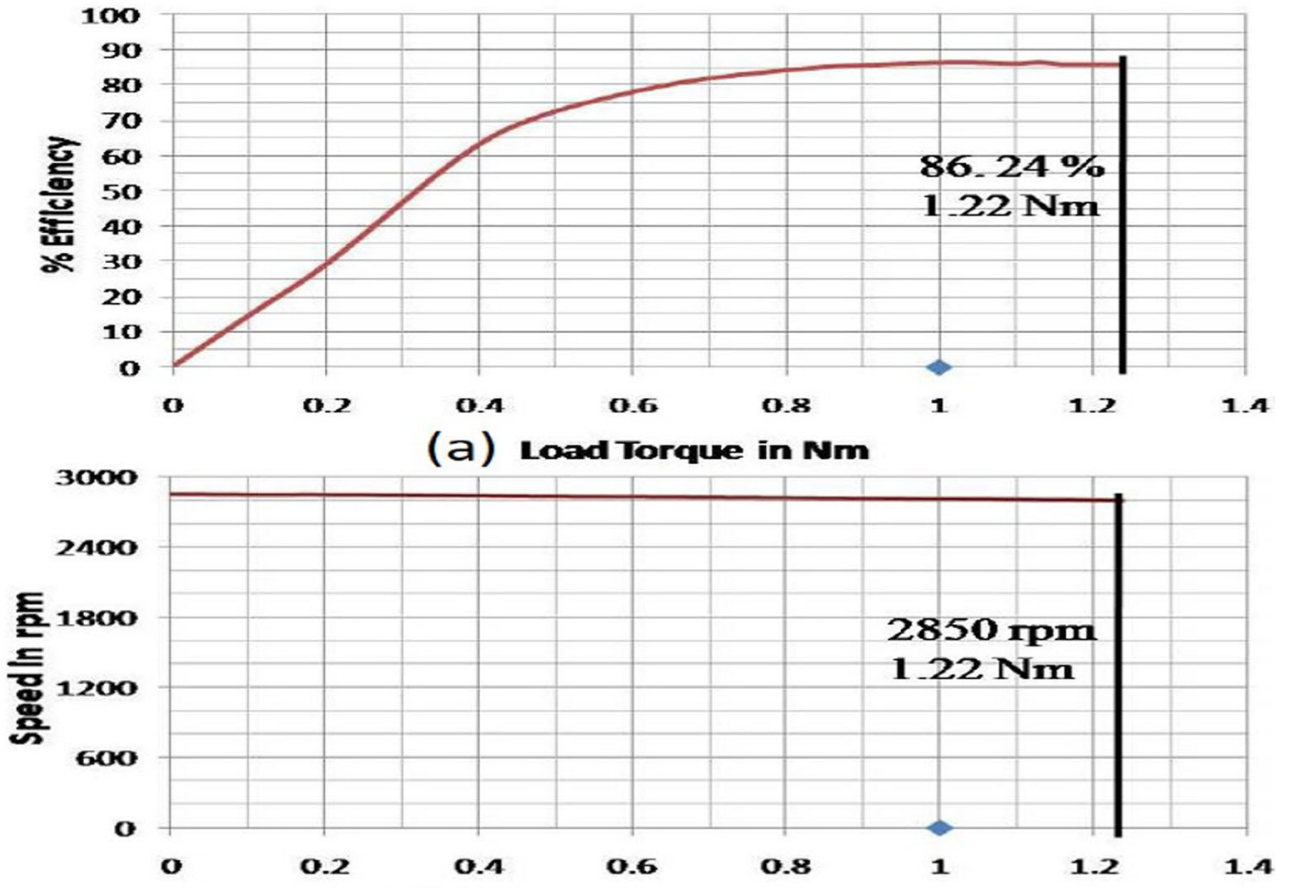

(b) Load Torque in Nm

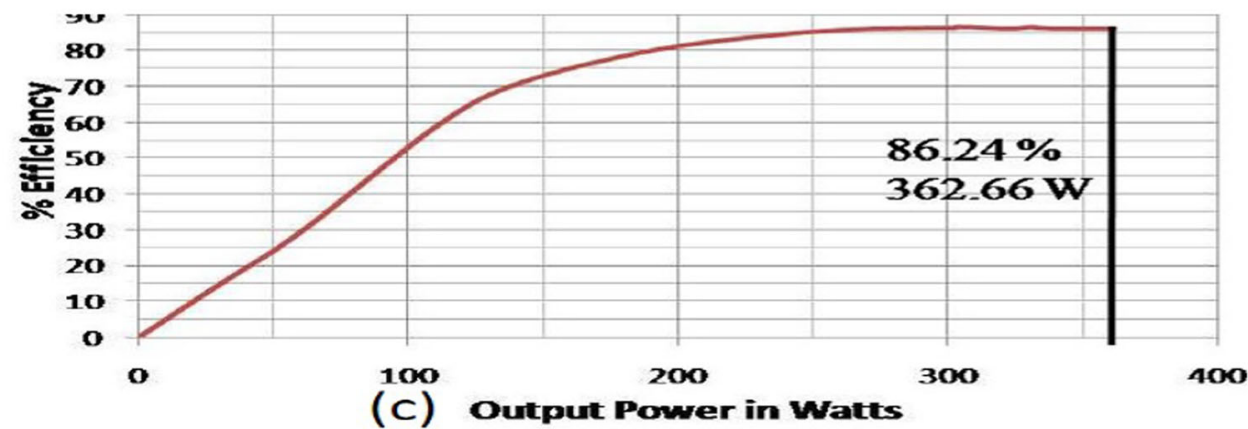

\section{Real Time Application of SRM Drive}

The alternate drive system with SRM instead of SPIM proposed in this work is considered for a real time application.

\section{Real Time Setup}

A prototype water lifting pump system along with SRM drive is setup. A centrifugal pump impeller acts as the load of the designed and fabricated $370 \mathrm{~W} 2850 \mathrm{rpm}$ motor. The whole setup along with the SRM drive is shown in Fig. 14. In this experiment, the bottom water storage tank is kept $1 \mathrm{~m}$ below the axis of pump (static suction lift) and the top tank is kept $5 \mathrm{~m}$ above the axis of pump (static discharge head). Thus the overall head between suction to delivery is maintained at $6 \mathrm{~m}$.

The experiment is conducted and the discharge capacity of the pump with rated input power is measured. The hydraulic power can be calculated as per the eq. (4).
$P=\frac{Q \times g \times H}{3600}$

The measured value of water discharge from the experiment is 2091 Litre Per Hour (LPH) with differential head of $6 \mathrm{~m}$. The output of the SRM drive at the rated condition has already been obtained from the experimental data as in Table 5. The overall experimental data of SRM pump system is represented in Fig. 15.

Table 5 Comparison of the simulated and experimental results of SRM

\begin{tabular}{lll}
\hline Parameters & FEM & Experimental \\
\hline Input Power (W) & 410.50 & 420.50 \\
Output Power (W) & 370 & 362.66 \\
Total Loss (W) & 40.50 & 57.84 \\
Efficiency (\%) & 90.13 & 86.24 \\
Rated Torque (N-m) & 1.24 & 1.24 \\
\hline
\end{tabular}




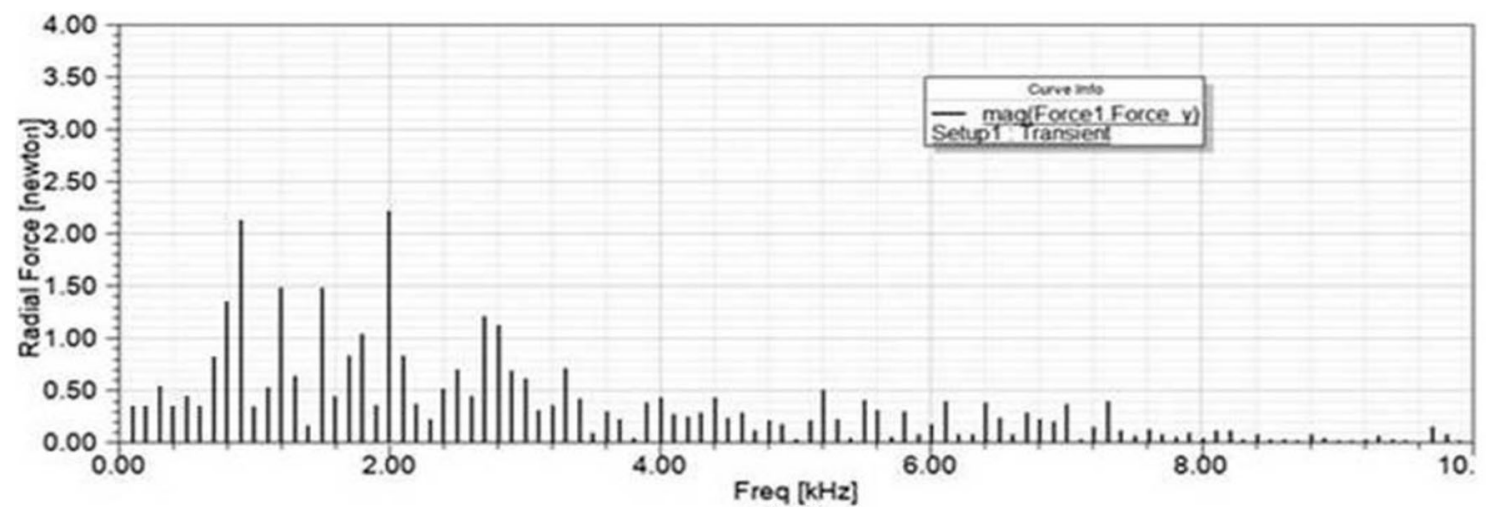

(a)

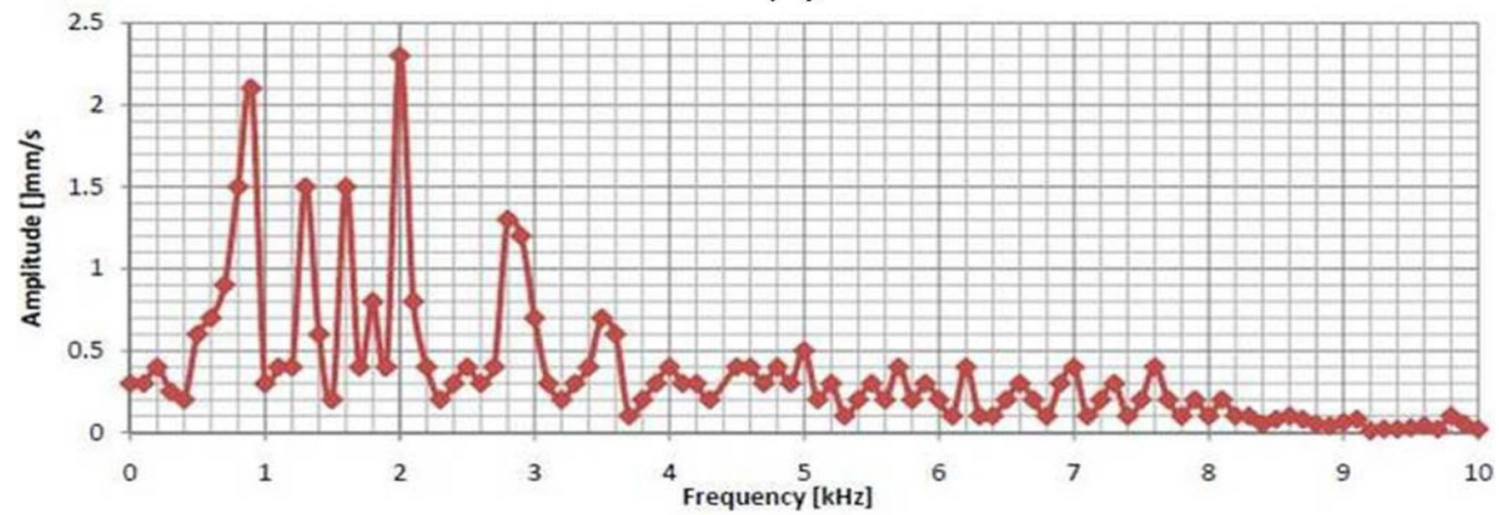

(b)

Fig. 11 a FFT on Radial forces, b Vibrations $(\mathrm{mm} / \mathrm{s})$

At present in agricultural applications SPIM is used. The efficiency of SPIM of same rating obtained by FE analysis is $72.22 \%$ [35]. It does not require a drive for water lifting purpose, since it is a constant speed application. The efficiency of SRM is obtained as $86.24 \%$ experimentally and $90.13 \%$ by FE analysis (Table 2). This includes the efficiency of the drive system also. It is clear that efficiency of SRM is much higher than SPIM making it the best candidate to be used as a motor for water lifting system.

\section{Economic Analysis}

In this section an economic analysis of water lifting system using SPIM and SRM drive is done. For an input of $370 \mathrm{~W}$, the output

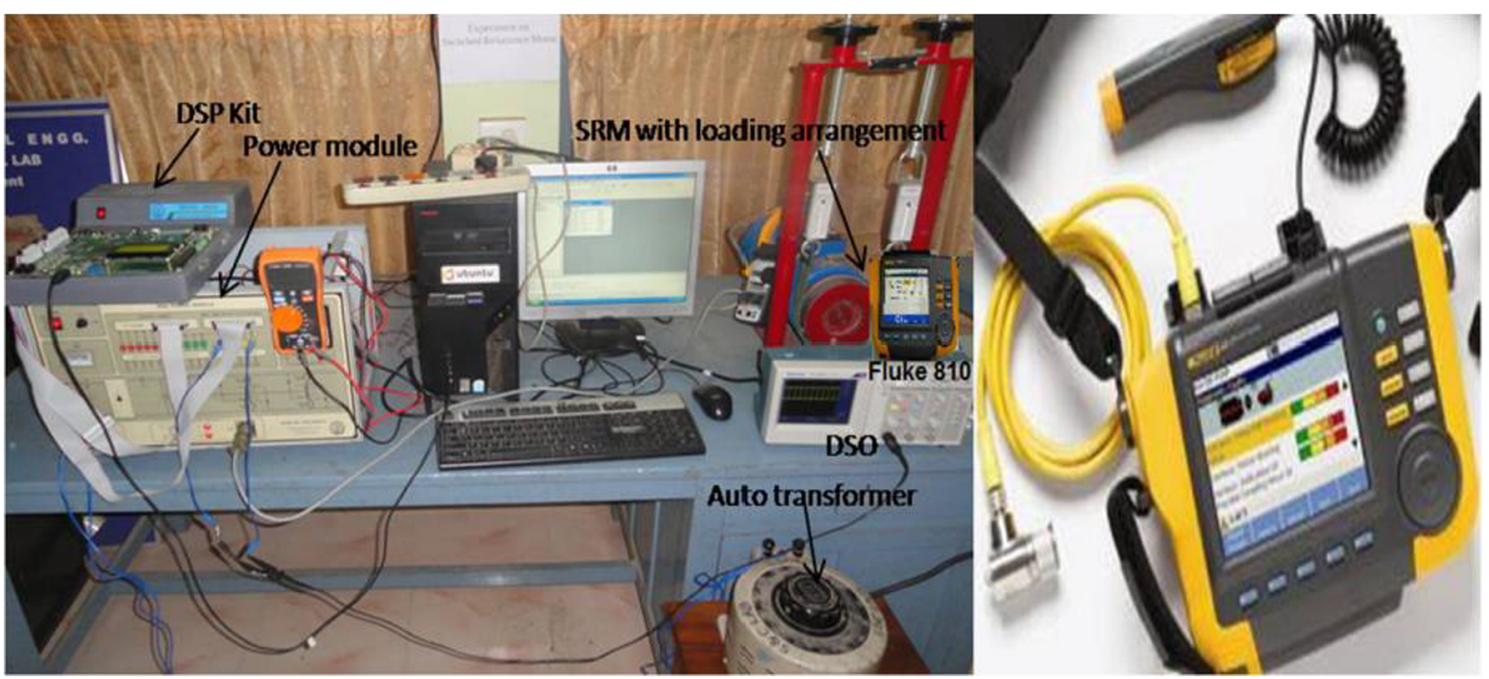

Fig. 12 Experimental setup of vibration measurement using Fluke 810 Vibration Tester 

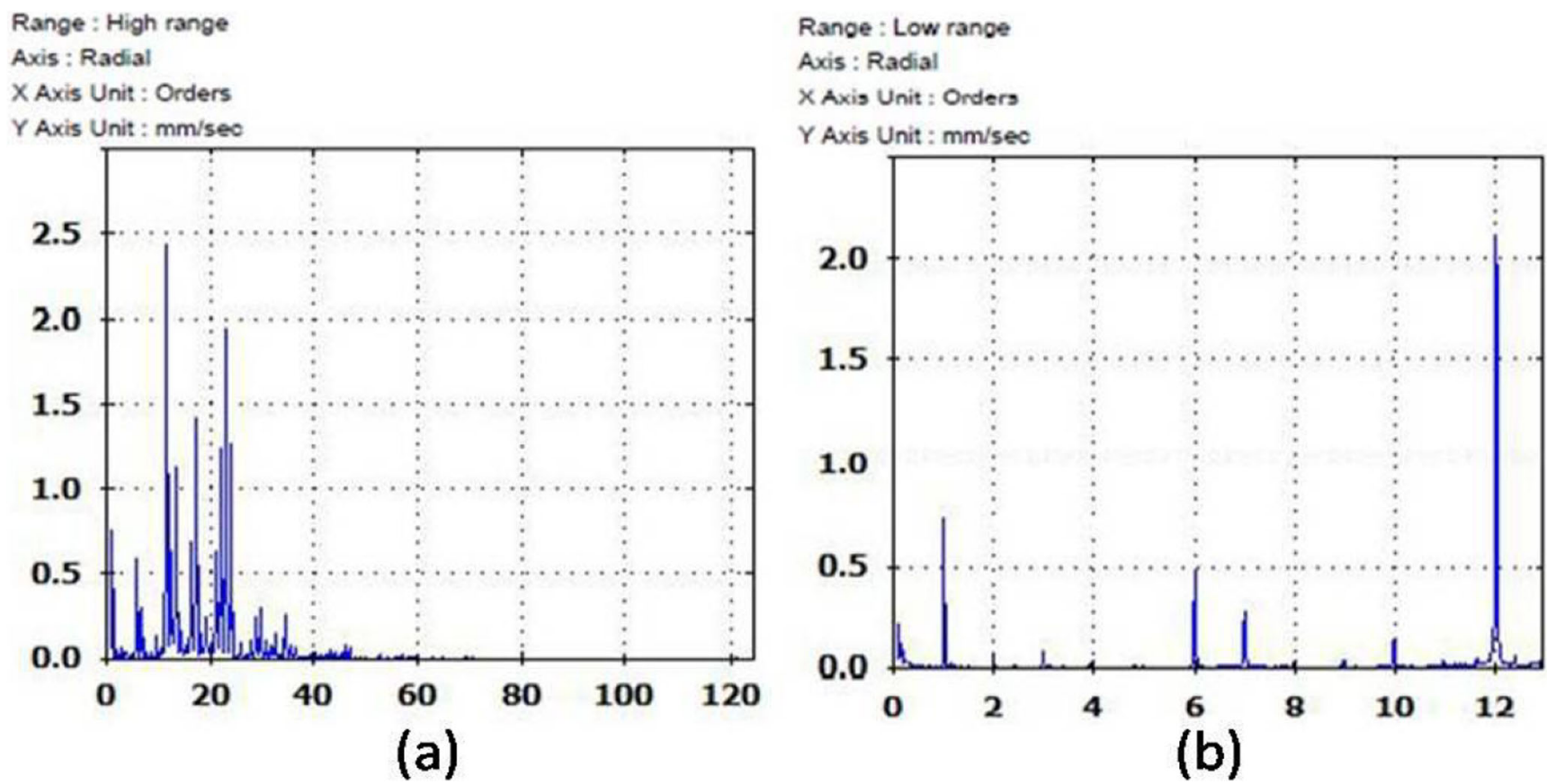

Fig. 13 a Low order frequency response of vibration for load of $1.22 \mathrm{Nm}$, b Higher order frequency response of vibration for load of $1.22 \mathrm{Nm}$

specifies by pump manufactures manual is 2200 LPH for $6 \mathrm{~m}$ head [40]. With these values, the overall system of the water lifting process in both cases are shown as in Fig. 16.

The prototype SRM drive discussed in the previous section is used for the analysis. In order to highlight the energy saving and economical benefits of using this drive system, it is compared with an SPIM based water lifting mechanism which is presently being used in agricultural fields. However, in the present work only FE data is available regarding SPIM and this data is utilized for the purpose of comparison.

\section{Calculation of Energy Consumption Based on FE Analysis}

The discharge $(\mathrm{Q})$ of single phase induction motor pump as per manufacturer's data is $2200 \mathrm{LPH}$. Time taken for the delivery of $20001 /$ day,

Fig. 14 Prototype of SRM drive with centrifugal pump and pipe connections
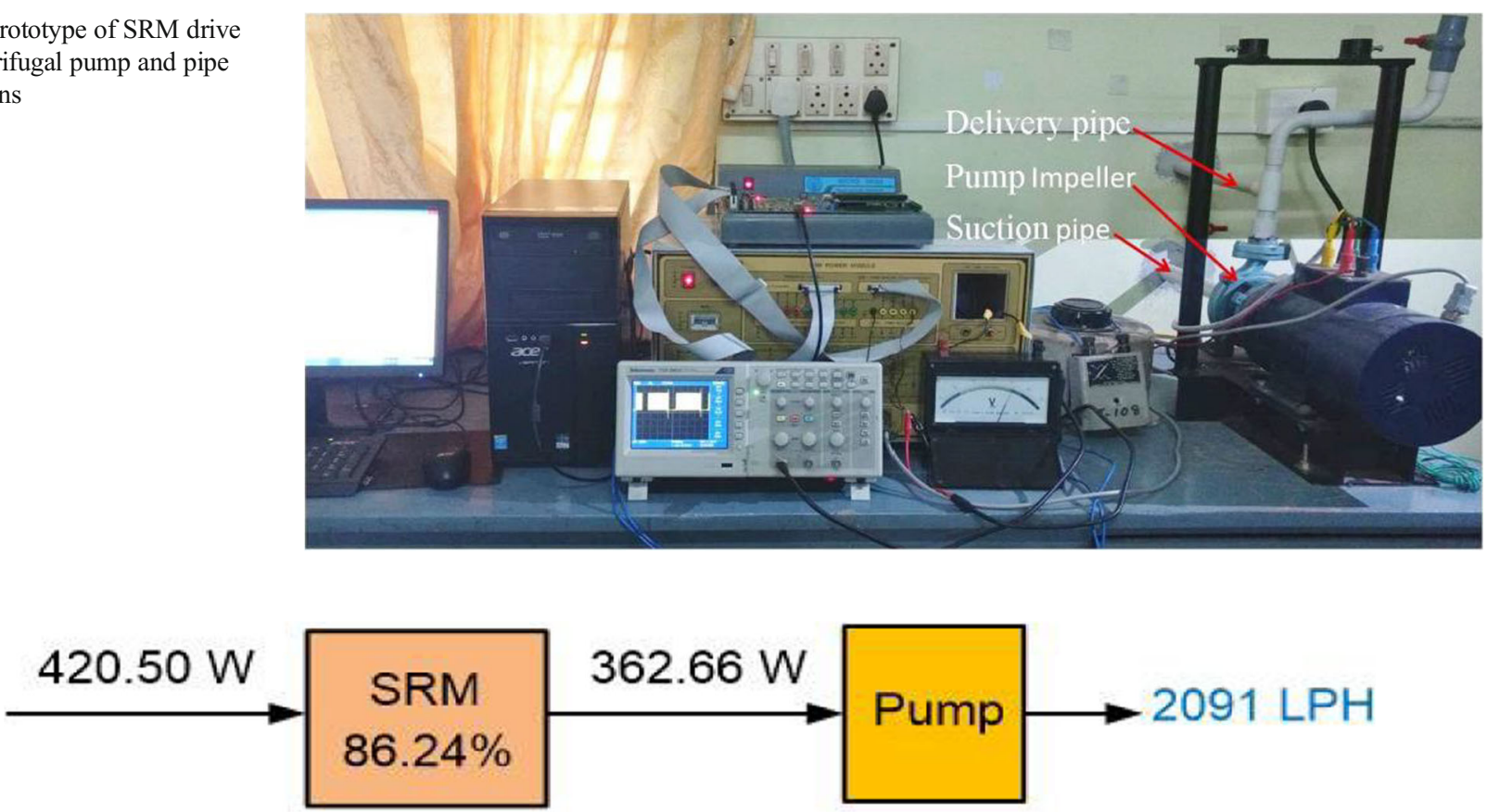

Fig. 15 System efficiency and output as per the real time experiment of SRM pump 
Fig. 16 System efficiency and output of SPIM and SRM pumps as per FEM analysis
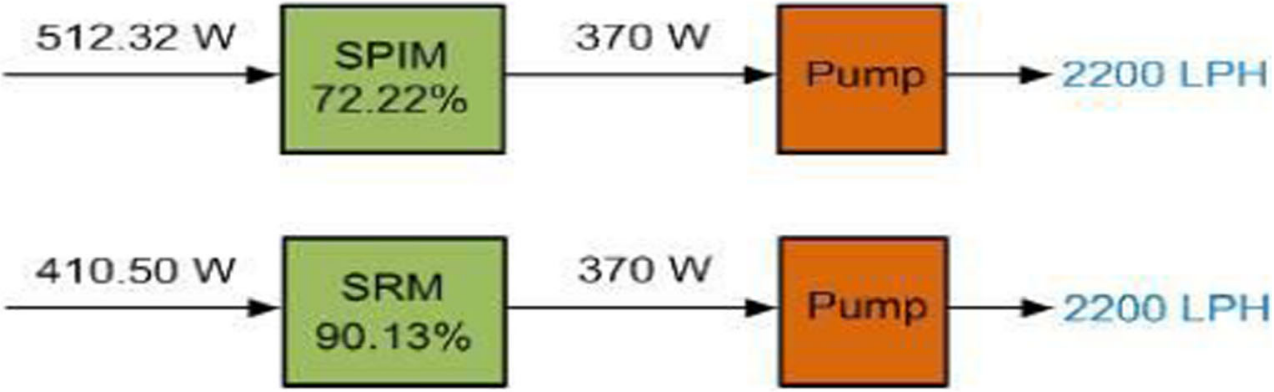

$=\frac{2000}{2200}=0.91$ hour

Based on this, energy consumption of SPIM pump per year,

$=(0.51232 \times 0.91) \times 365=170 \mathrm{kWh}$

For SRM pump, energy consumption per year,

$=(0.4105 \times 0.91) \times 365=137 \mathrm{kWh}$

For the same discharge capacity of the pump, the energy units consumed in an SPIM based system is $170 \mathrm{kWh}$ per year, whereas if it is replaced by SRM drive, the energy consumed is only $137 \mathrm{kWh}$ per year for the water lifting based on FE Analysis leading to a saving of 33 units per year.

\section{Calculation of Energy Consumption of SRM Pump Based on Experimental Analysis}

From the experimental analysis, time taken for the delivery of 2000 1/day,

$=\frac{2000}{2091}=0.956$ hour

For SRM pump, energy consumption per year,

$=(0.4205 \times 0.956) \times 365=147 \mathrm{kWh}$

The real time experimental results also reveal that the energy consumption of SRM drive is considerably less than that of SPIM. The results are tabulated in Table 6. The FEM and real

Table 6 Energy consumption for an year of SPIM and SRM Drives

\begin{tabular}{llll}
\hline Parameters & SPIM & SRM & \\
\cline { 3 - 4 } & FEM & FEM & Experimental \\
\hline Discharge Capacity of Pump (kg/h) & 2200 & 2200 & 2091 \\
Time taken for lifting 2000 Litres (h) & 0.91 & 0.91 & 0.956 \\
Units per day & 0.466 & 0.374 & 1.402 \\
Units per year & 170 & 137 & 147 \\
Units saving per year (FEM) 33 Units & & & \\
\hline
\end{tabular}

time comparison show that the SRM drive is a very efficient drive system which can be used for the water lifting application.

\section{Conclusion}

Replacement of existing motors used in agricultural applications with drive systems and flexible speed controllers can bring in not only efficiency enhancement, but also additional functional features. This paper investigated how the Switched Reluctance Motor (SRM) perform energy efficiency compared to commonly used Single Phase Induction Motor (SPIM) in water lifting applications. The analytical and FE analysis shows that the efficiency of SRM drive is as high as 90.13\% whereas the SPIM provides only an efficiency of $72.22 \%$ under similar operating conditions, thereby establishing the superiority of SRM over SPIM. The drive system is modelled and the speed regulation capabilities are determined on Matlab platform. The performance analysis of SRM drives through simulations reveal the capability of SRM to respond to different reference speeds at high starting torque in a better manner. This is further validated by experimentally. Hence the SRM with its high efficiency, rugged construction, ability to give good performance at different speeds, is a better suited machine to be used in agriculture applications. The vibration measurement shows that for the designed drive system, vibration is under control. The massive saving in energy consumption in water pumps used in agricultural sector with proposed SRM drive system is established by a real time implementation. The analysis detailed in the paper emphatically proves the immense potential in achieving huge energy saving when the capability of SRM is utilized by a major energy consumer sector like agriculture in future.

\section{References}

1. Ministry of statistics and programme implementation, Energy statistics 2018, Government of India, 2018

2. Hassan Moghbelli, Gayle E. Adams, and Richard G. Hoft, Performance of a 10-HP Switched Reluctance Motor and 
Comparison with Induction Motor, IEEE Transaction on Industrial Application, vol. 27, no. 3, pp. 531-538, May/June 1991

3. A. Asok kumar, Bindu G.R. and Gopinath Dinesh, Performance analysis of single phase induction motor and switched reluctance motor used in domestic appliances with a view of energy conservation, Electrical Engineering/Electronics, Computer, Telecommunications and Information Technology (ECTI-CON), IEEE, 2014

4. Vijayakumar K, Karthikeyan R, Paramasivam S, Arumugam R, Srinivas K (2008) Switched reluctance motor modeling, design, simulation, and analysis: a comprehensive review. IEEE Trans Magn 44(12):4605-4617

5. Hannoun H, Hilairet M, Marchand C (2010) Design of an srm speed control strategy for a wide range of operating speeds. IEEE Trans Ind Electron 57(9):2911-2921

6. Rahman K (2000) M and Fahimi, Babak and Suresh, Gopalakrishnan and Rajarathnam, Anandan Velayutham and Ehsani, M, advantages of switched reluctance motor applications to EV and HEV: design and control issues. IEEE Trans Ind Appl 36(1):111-121

7. N. Scho_eld and S. Long, Generator operation of a switched reluctance starter/generator at extended speeds, IEEE Transactions on Vehicular Technology, vol. 58, no. 1, pp. 48-56, 2009

8. Li S, Zhang S, Dang J, Habetler TG, Harley RG (Sept. 2019) Analytical calculation of the phase inductance profile of switched reluctance machines. IEEE Transactions on Energy Conversion 34(3):1149-1163

9. A. Semon and A. Crăciunescu, "Study to Increase the Efficiency of the Electric Drive System of a Vehicle at Different Speeds," 11th International Symposium on Advanced Topics in Electrical Engineering (ATEE), Bucharest, Romania, pp. 1-7, 2019

10. Liu C (Dec. 2018) Emerging electric machines and drives - an overview. IEEE Transactions on Energy Conversion 33(4):2270-2280

11. Reinert J, Inderka R, Menne M, De Doncker RW (2000) Optimizing performance in switched-reluctance drives. IEEE Ind Appl Mag 6(4):63-70

12. J. Kim and R. Krishnan, Single-controllable-switch-based switched reluctance motor drive for low-cost variable-speed applications, in Energy Conversion Congress and Exposition, (ECCE), IEEE, pp. 2535-2542, 2009

13. Amit Kumar Jain, Ned Mohan, Dynamic Modelling, Experimental Characterization, and Verification for SRM Operating With Simultaneous Two-Phase Excitation, IEEE Transaction on Industrial Electronics, vol. 53, no. 4, pp. 1238-1249, August 2006

14. Hrabovcov V, Rafajdus P, Liptk M, Szab L (2013) Performance of converters suitable for switched reluctance generator (srg) operation. J Electr Eng 64(4):201-211

15. Hosseini, Hosssein, Behrooz Tousi, Navid Razmjooy, and Mohsen Khalilpour. "Design robust controller for automatic generation control in restructured power system by imperialist competitive algorithm." IETE Journal of Research 59, no. 6, pp. 745-752, 2013

16. Razmjooy, Navid, and Mohsen Khalilpour. "A Robust Controller For Power System Stabilizer By Using Artificial Bee Colony Algorithm." Tech J Engin \& App Sci 5, no. 3, pp. 106-113, 2015

17. Razmjooy, Navid, Ali Madadi, and Mehdi Ramezani. "Robust Control of Power System Stabilizer Using World Cup Optimization Algorithm." International Journal of Information, Security, and Systems Management 5, no. 1, pp. 524-531, 2016

18. Hosseini, Hossein, Behrooz Tousi, and Navid Razmjooy. "Application of fuzzy subtractive clustering for optimal transient performance of automatic generation control in restructured power system." Journal of Intelligent \& Fuzzy Systems 26, no. 3, pp. 1155-1166, 2014

19. Kiruthika D, Susitra D (2014) Speed controller of switched reluctance motor. Indian J Sci Technol 7(8):1043-1048

20. Tahour A, Meroufel A, Abid H, Aissaoui AG (2008) Sliding controller of switched reluctance motor. Leonardo Electronic Journal of Practices and Technologies 12:151-162
21. B. S. Ali, H. M. Hasanien, and Y. Galal, "Speed control of switched reluctance motor using artificial neural network controller," in Computational Intelligence and Information Technology. Springer, 2011, pp. 6-14

22. Harnefors L, Saarakkala SE, Hinkkanen M (2013) Speed control of electrical drives using classical control methods. IEEE Trans Ind Appl 49(2):889-898

23. Rasilo P, Lemesle M-A, Belahcen A, Arkkio A, Hinkkanen M (2014) Comparison of finite-element-based state-space models for pm synchronous machines. IEEE Transactions on Energy Conversion 29(2):535-543

24. S. R. A. Arani and B. Ganji, Performance prediction of switched reluctance motor under eccentricity fault, 2017 IEEE International Conference on Environment and Electrical Engineering and Industrial and Commercial Power Systems Europe (EEEIC/ I\&CPS Europe), pp. 1-6, 2017

25. Balamurugan S, Arumugam R (2005) Estimation of vibrations in switched reluctance motor drives. Am J Appl Sci 2(4):791-795

26. Panda D, Ramanarayanan V (2007) Reduced acoustic noise variable dc-bus-voltage-based sensorless switched reluctance motor drive for hvac applications. IEEE Trans Ind Electron 54(4):2065-2078

27. Long SA, Zhu Z, Howe D (2005) Effectiveness of active noise and vibration cancellation for switched reluctance machines operating under alternative control strategies. IEEE Transactions on Energy Conversion 20(4):792-801

28. Chai J, Lin Y, Liaw C (2006) Comparative study of switching controls in vibration and acoustic noise reductions for switched reluctance motor. IEE Proceedings-Electric Power Applications 153(3):348-360

29. Makino H, Kosaka T, Matsui N (2015) Digital pwm-control-based active vibration cancellation for switched reluctance motors. IEEE Trans Ind Appl 51(6):4521-4530

30. R. Davis, W. Ray, and R. Blake, "Inverter drive for switched reluctance motor: circuits and component ratings," in IEE Proceedings B (Electric Power Applications), vol. 128, no. 2. IET, 1981, pp. 126-136

31. M. Ehsani, J. T. Bass, T. J. Miller, and R. L. Steigerwald, "Development of a unipolar converter for variable reluctance motor drives," IEEE transactions on industry applications, no. 3, pp. 545553,1987

32. Vukosavic S, Stefanovic VR (1991) Srm inverter topologies: a comparative evaluation. IEEE Trans Ind Appl 27(6):1034-1047

33. Ahn J-W, Liang J, Lee D-H (2010) Classification and analysis of switched reluctance converters. Journal of Electrical Engineering and Technology 5(4):571-579

34. Barnes M, Pollock C (1998) Power electronic converters for switched reluctance drives. IEEE Trans Power Electron 13(6):1100-1111

35. Asok Kumar A., and Bindu G. R., Energy efficient drive system for domestic and agriculture applications: a comparative study of SPIM and SRM drives, 19th international conference on industrial technology (ICIT2018), IEEE 2018

36. Zhong D (2009) Finite element analysis of synchronous machines. Dissertation, December

37. Krishnan R (2001) Switched reluctance motor drives: modeling, simulation, analysis, design, and applications. CRC press

38. R. Krishnan, Electrical motor drives- modeling, analysis and control, Printice-Hall of India Private Limited, 2007

39. Zhou, Yang and Bao, Xiaohua and Di, Chong and Wang, Lang, Analysis of dynamic unbalanced magnetic pull in induction motor with dynamic eccentricity during starting period, IEEE Transactions on Magnetics, vol. 52, no.7,pp 1-4, 2016

40. High-pressure pumps for low-stress water solutions, V-Guard Industries Ltd., 2018

Publisher's Note Springer Nature remains neutral with regard to jurisdictional claims in published maps and institutional affiliations. 